\title{
The Characteristics and Relationship of Parental Sexual Knowledge and Sex Education Attitude to Young Children
}

\author{
Xin Jin \\ Teacher Education School, Nanjing Normal University Taizhou College, Taizhou, China \\ Email: jina1989728@163.com
}

How to cite this paper: Jin, X. (2021). The Characteristics and Relationship of Parental Sexual Knowledge and Sex Education Attitude to Young Children. Creative Education, 12, 2002-2010.

https://doi.org/10.4236/ce.2021.129153

Received: August 13, 2021

Accepted: September 4, 2021

Published: September 7, 2021

Copyright $\odot 2021$ by author(s) and Scientific Research Publishing Inc. This work is licensed under the Creative Commons Attribution International License (CC BY 4.0).

http://creativecommons.org/licenses/by/4.0/

\section{(c) (i) Open Access}

\begin{abstract}
Parents' sufficient and correct sexual knowledge and positive attitude towards sex education are the prerequisites for carrying out family sex education. Through a questionnaire survey on the sexual knowledge and attitudes towards sex education of 1729 parents of children in senior classes (5 - 6 years old), the study found that parents' sexual knowledge and sex education attitude were generally good, but the dimensions were uneven. Among them, the "children development" dimension of sex knowledge was the lowest, and the "obstacles of sex education" dimension was the lowest in the attitude of sex education; among the three background variables of parent's gender, age and education background, the main effect of parent's gender and education background on sexual knowledge and attitude towards sex education were significant.
\end{abstract}

\section{Keywords}

Parents of Young Children, Sexual Knowledge, Sex Education Attitude, Characteristics

\section{Introduction}

Sex education is an education that uses scientific sexual knowledge, correct sexual attitude and appropriate teaching methods to cultivate children's sound sexual attitude, promote children's harmonious relationship between men and women, and guide children's sound development at all levels of physiology, psychology and society (Chuang, 2009). Sex education is an organic part of shaping healthy personality and lays a foundation for the development of an individual's life. Studies have shown that appropriate sex education can allow young people 
to analyze themselves and reduce the occurrence of dangerous sexual behaviors, which is of great significance to the psychological development of young people (Berglas et al., 2016). Parents understand and actively help their children answer questions about sexual knowledge, which will help to cultivate their children's sense of responsibility and healthy personality, and will be more intelligent in dealing with sexual problems in the future (Liu, 2008). At present, most domestic studies on sex education focus on adolescent children. A survey also found that most urban parents believe that the best starting age for children's sex education is 13 - 18 years old (Liu \& Caroline, 2007). Adolescent sex education is the focus of sex education, but the critical period of sex education should be before 5 years old (Chuang, 2009). At this stage, children are in the psychological development stage of "sexual organ stage" who can recognize the difference between men and women and will produce a lot of sexual curiosity behaviors. This is a good time to carry out sex education. Studies have found that the time when the family starts sex education affects the implementation of family sex education in adolescence (Yang \& Wang, 2018). If parents start talking about sex when their children are very young, family sex education will be smoother with the growth of their children's age; On the contrary, it will be very difficult to wait until children grow up (Wilson et al., 2010). Therefore, it can be said that the early childhood is the critical period and the initial stage of sex education. Correct and scientific sex education for children during this period is very important to the child's physical and psychological health (Qin \& Li, 2017).

The family is the first classroom in carrying out sex education, and parents are the first teachers of children's sex education. The implementation of family sex education is affected by parents' attitudes and abilities towards sex education, specifically by parents' understanding of children's sexual development, their emphasis on children's sex education, and whether they have the skills to communicate with children, etc. In the long-term parent-child interaction, parents can directly or indirectly affect children's knowledge and attitude towards sex in the most natural way (Zhang et al., 2019). Parents' sexual knowledge and attitudes towards sex education play a vital role. Parental sexual knowledge refers to the correct degree of parents' understanding of children's "sexual” knowledge which is the basic condition for carrying out sex education. If parents lack sex knowledge, their willingness to carry out sex education will be reduced (Byers et al., 2008). Parental sex education attitude refers to parents' views on the implementation of sex education in early childhood which is the core of the implementation of sex education. Parents' attitude towards sex education will affect their own behaviors and parenting styles, thus affecting children's knowledge and perceptions of sex in a subtle way. Therefore, it can be said that the prerequisite for the effective development of family sex education is that parents have sufficient and positive children sex knowledge and a positive attitude towards children sex education.

As the first teachers of their children, parents have the responsibility to be the basic source of their children's correct sexual knowledge and attitudes. In reality, 
parents do not play a corresponding role in providing correct sexual information for their children. The main sources of people's access to sexual information are the media, friends, peers and school (Liu \& Caroline, 2007). If misled by wrong information, it may cause children to form wrong knowledge about sex. At present, there is a relative deficiency of research on early childhood sex education and early childhood family sex education. This study intends to take the parents of young children as the research object to explore the basic characteristics of parental sexual knowledge and sex education attitude, and to further explore the relationship between the two variables, in order to provide a reference for the development of young children's family sexual education.

\section{Methodology}

\subsection{Research Object}

The study adopted a quantitative approach. A total of 1852 questionnaires were collected from parents of senior class kids ( 5 - 6 years old) in 9 public kindergartens by online survey. The participants were randomly selected. Excluding the non-parental questionnaires of the respondents, 1729 valid questionnaires were finally obtained, with an effective recovery rate of $93 \%$. Nearly $76.7 \%$ participants were mothers and $23.3 \%$ were fathers. $7.6 \%$ participants were under 30 years old, $61.3 \%$ were 31 to 35 years old, $23.5 \%$ were 36 to 40 years old, and nearly $7.6 \%$ were over 41 years old. $30.9 \%$ of parents' educational background were below high school, $38.1 \%$ were college degree, $28.3 \%$ were bachelor degree, and nearly $2.7 \%$ were master degree and above.

\subsection{Instrument}

The first instrument used in the study was the Parental Sexual Knowledge (PSK) developed by Chuang (2009) and compiled combined with the needs of this study. The questionnaire with 15 items was divided into three dimensions: children development (1 - 5), health care (7 - 11), and sexual harassment prevention (12 - 16). The responses were weighted in terms of a scale of 5-point Likert-type in which each scale was given from "very non-conforming" to "very consistent". Among them, the 12th to 15th questions in the sexual harassment prevention dimension were reverse questions, and the scores were converted during data processing. The final score was the average score of the cumulative sum of each item. The higher the score, the higher the parents' understanding of children's sexual knowledge.

The second instrument was Parental Sex Education Attitude (PSEA), mainly based on the research of Chuang (2009) and Liao Peijun (2016), combined with the needs of this research. The scale consisted of 15 items, for which parents responded on a 5-point Likert self-report scale ranging from 1 (strongly disagree) to 5 (strongly agree). Three dimensions were contained in the scale: general sex education attitude (questions 1 - 6), benefits of sex education (questions 7 - 9), and obstacles of sex education (questions 10 - 15). Among them, the sixth ques- 
tion in the general sexual education attitude and the sixth question in the implementation of sexual education obstacles were reverse questions, and the scores were also converted. The final score was the average score of the cumulative sum of each item. The higher score indicated that parents held more positive attitude towards education.

A Cronbach alpha analysis of the reliability of the measurement of the variables involved in the two questionnaires showed alpha of 0.790 and 0.864 respectively.

\subsection{Data Analysis}

Data for the study were analyzed by using SPSS for Windows, version 22.0. The descriptive statistics, frequencies and percentages of categorical variables and the means and standard deviations of numeric variables were calculated. Numerical variables were investigated by independent sample $t$-test and one-way analysis of variance (ANOVA) at 0.05 level of significance. When the statistically significant difference was found in one-way ANOVA, pairwise comparisons were performed using post hoc Scheffe test. Finally, we analyzed the correlations of variables in two questionnaire.

\section{Results}

\subsection{The Overall Status of Parental Sexual Knowledge and Sex Education Attitude}

In order to carry out a horizontal comparison between different dimensions, the total scores of parental sexual knowledge and sex education attitude were divided into four levels: low, lower, middle, and high according to the quartile interval. The specific grouping results were: each dimension of sexual knowledge below 3.467 was divided into low level, 3.467 - 3.867 was middle-low level, 3.867 - 4.267 was middle-upper level, and higher than 4.267 was high level; each dimension of sex education attitude was less than 3.6 points Low level, 3.6 - 4.067 was the lower-middle level, 4.067 - 4.467 was the upper-middle level, and higher than 4.467 was the high level.

The mean scores and SDs of both the PSK and PSEA were shown in Table 1, and the level distributions of each dimension were shown in Table 2. The results indicated that the advantages of PSK were in the two dimensions of "health care" and "sexual harassment prevention", but the disadvantage was the lack of attention to "children development". Among them, there was a relatively correct and consistent understanding of the "health care" dimension. Although the overall cognition of "sexual harassment prevention" was at the middle and upper level, nearly one-third of parents still had insufficient knowledge of this dimension. The specific distribution of the various dimensions at different levels of PSEA indicated that most parents had a positive attitude toward the implementation of sex education, but they had relatively conservative attitude cause of more obstacles. 
Table 1. Overall level of PSK and PSEA.

\begin{tabular}{lccc}
\hline \multirow{2}{*}{ Variable } & \multicolumn{3}{c}{ Descriptive Analysis Results } \\
\cline { 2 - 4 } & $\mathrm{M}$ & $\mathrm{SD}$ & Level \\
\hline PSK (children development) & 3.36 & 0.93 & low \\
PSK (health care) & 4.28 & 0.74 & high \\
PSK (sexual harassment prevention) & 3.91 & 0.84 & middle-upper \\
PSEA (general sex education attitude) & 4.18 & 0.69 & middle-upper \\
PSEA (benefits of sex education) & 4.26 & 0.77 & middle-upper \\
PSEA (obstacles of sex education) & 3.65 & 0.84 & middle-low \\
\hline
\end{tabular}

Table 2. Distribution of PSK and PSEA at different levels $(\mathrm{N}=1729)$.

\begin{tabular}{ccccccc}
\hline \multirow{2}{*}{ Level } & \multicolumn{3}{c}{ PSK } & \multicolumn{3}{c}{ PSEA } \\
\cline { 2 - 6 } & $\begin{array}{c}\text { children } \\
\text { development }\end{array}$ & health care & $\begin{array}{c}\text { sexual } \\
\text { harassment } \\
\text { prevention }\end{array}$ & $\begin{array}{c}\text { general sex } \\
\text { education } \\
\text { attitude }\end{array}$ & $\begin{array}{c}\text { benefits of sex } \\
\text { education }\end{array}$ & $\begin{array}{c}\text { obstacles of } \\
\text { sex education }\end{array}$ \\
\hline \multirow{2}{*}{ low } & 964 & 217 & 554 & 302 & 232 & 745 \\
& $(55.8 \%)$ & $(12.6 \%)$ & $(32.0 \%)$ & $(17.5 \%)$ & $(13.4 \%)$ & $(43.1)$ \\
middle-low & 273 & 158 & $\%)$ & 393 & 489 & 433 \\
& $(15.8 \%)$ & $(9.1 \%)$ & $(13.2$ & $(22.7 \%)$ & $(28.3 \%)$ & $(25.0 \%)$ \\
middle-upper & 199 & 332 & 341 & 294 & 196 & 217 \\
& $(11.5 \%)$ & $(19.2 \%)$ & $(19.7 \%)$ & $(17.0 \%)$ & $(11.3 \%)$ & $(12.6 \%)$ \\
high & 293 & 1022 & 606 & 740 & 812 & 334 \\
& $(16.9 \%)$ & $(59.1 \%)$ & $(35.0 \%)$ & $(42.8 \%)$ & $(47.0 \%)$ & $(19.3 \%)$ \\
\hline
\end{tabular}

\subsection{Effect of Parental Background Variables on Sexual Knowledge and Sex Education Attitude}

As given in Table 3, three-factor independent sample variance analysis was used to analyze the influence of parents' gender, age, and education background on PSK and PSEA.

The results showed that the gender of parents had a significant effect on PSK $(\mathrm{F}[1,1705]=11.01, p=0.001)$. For score from fathers $(\mathrm{M}=3.66, \mathrm{SD}=0.66)$ was significantly smaller than mothers $(\mathrm{M}=3.90, \mathrm{SD}=0.56)$, indicating that the mother had a higher level of knowledge about children sexual knowledge than the father. There was no significant effect on their sex knowledge, indicating that PSK was not affected by parents' age $(P>0.05)$. Parents' educational background had a significant effect on their PSK $(\mathrm{F}[2,1705]=9.62, p<0.001)$. Scheffe's post-mortem comparison found high school and below $(\mathrm{M}=3.70, \mathrm{SD}=0.61)$ was significantly less than that of junior college $(\mathrm{M}=3.85, \mathrm{SD}=0.57)$, and that of junior college was significantly less than that of undergraduate and above (M $=3.99, \mathrm{SD}=0.56)$. It showed that the higher the education level of the parents, the higher the understanding of children's sexual knowledge; in terms of the impact on sexual knowledge, the interaction of the parents' gender, age, and education level was not significant. 
Table 3. Analysis of variance of parents' background information on PSK and PSEA.

\begin{tabular}{|c|c|c|c|c|c|c|}
\hline Variable & & SS & df & MS & $\mathrm{F}$ & $p$ \\
\hline \multirow{2}{*}{ A parents' gender } & PSK & 3.60 & 1 & 3.60 & 11.01 & 0.001 \\
\hline & PSEA & 2.42 & 1 & 2.42 & 6.76 & 0.009 \\
\hline \multirow{2}{*}{ B parents' age } & PSK & 1.18 & 3 & 0.39 & 1.20 & 0.31 \\
\hline & PSEA & 1.26 & 3 & 0.42 & 1.17 & 0.32 \\
\hline \multirow{2}{*}{$\begin{array}{l}\text { C parents' education } \\
\text { background }\end{array}$} & PSK & 6.29 & 2 & 3.15 & 9.62 & $<0.001$ \\
\hline & PSEA & 4.76 & 2 & 2.38 & 6.65 & 0.001 \\
\hline \multirow{2}{*}{$A^{*} B$} & PSK & 0.40 & 3 & 0.13 & 0.41 & 0.75 \\
\hline & PSEA & 0.14 & 3 & 0.05 & 0.13 & 0.94 \\
\hline \multirow{2}{*}{$\mathrm{A}^{*} \mathrm{C}$} & PSK & 0.32 & 2 & 0.16 & 0.49 & 0.62 \\
\hline & PSEA & 0.45 & 2 & 0.23 & 0.63 & 0.53 \\
\hline \multirow{2}{*}{$\mathrm{B}^{\star} \mathrm{C}$} & PSK & 2.14 & 6 & 0.36 & 1.09 & 0.37 \\
\hline & PSEA & 2.40 & 6 & 0.40 & 1.12 & 0.35 \\
\hline \multirow{2}{*}{ deviation } & PSK & 557.91 & 1705 & 0.33 & & \\
\hline & PSEA & 610.45 & 1705 & 0.36 & & \\
\hline \multirow{2}{*}{ Total } & PSK & 606.87 & 1728 & & & \\
\hline & PSEA & 645.77 & 1728 & & & \\
\hline
\end{tabular}

Parents' gender also had a significant effect on PSEA $(\mathrm{F}[1,1705]=6.76, p=$ $0.009)$. For score from fathers $(\mathrm{M}=3.83, \mathrm{SD}=0.64)$ was significantly smaller than the mother $(\mathrm{M}=4.04, \mathrm{SD}=0.59)$ which indicated that mothers had a more positive attitude towards sex education than the fathers. Similarly, the age of the parents had no significant effect on PSEA $(p>0.05)$ which showed that parents' attitude towards sex education was not affected by their age. Parents' education background had a significant effect on their sex education attitude $(\mathrm{F}[2,1705]=$ $6.65, p=0.001)$. Scheffe's post-mortem comparison found that high school and below $(M=3.87, S D=0.63)$ was significantly less than junior college $(M=4.01$, $\mathrm{SD}=0.57)$, but there was no significant difference between junior college and undergraduate $([\mathrm{M}=4.08, \mathrm{SD}=0.61][p=0.08])$, and score from the high school and below was significantly smaller than undergraduate and above. The finding indicated that the level of education had a certain impact on the parents' attitudes towards sex education. When the parents' level of education was low (high school and below), their attitude towards sex education was relatively negative. In terms of the impact on attitudes towards sex education, the interaction of parental gender, age, and education level was not significant.

\section{Discussion}

This study revealed that parents' sexual knowledge and attitude towards sex education were generally good, indicating that parents had generally recognized the importance of young children's sex education, which was consistent with 
previous research results (Liu \& Caroline, 2007). However, a further comparison of each dimension with the total score revealed that parents' mastery of different dimensions of sex knowledge and attitudes towards sex education were not balanced. In terms of sexual knowledge, the level of "children development" was the weakest, and the dimensions of "health care" and "sexual harassment prevention" were relatively high. The reason could be understood from the perspective of the source of parents' sexual knowledge. Parents had higher scores in the dimensions of "health care" and "sexual harassment prevention". On the one hand, that was derived from their own life experience, and on the other hand, might be affected by external information (such as child sexual assault cases exposed by the media). However, there was a lack of attention to the development of human sexual psychology, especially for young children, whether in personal experience, external information, or the education experience that parents had received in the past. Attitudes towards sex education were generally positive, and the level was relatively low only in the dimension of "obstacles of sex education". It could be seen that although parents were very supportive of early childhood sex education, they also showed many concerns. On the one hand, it might be due to lack of sexual education knowledge and communication skills, and on the other hand it was also related to the lack of the insufficient publicity of sex education. Therefore, parents did not have enough awareness and ability to carry out children sex education (Zhang et al., 2019).

Consistent with the previous research result (Liu \& Caroline, 2007), this study found that the scores of mothers' sexual knowledge and sexual education attitude are significantly higher than those of fathers. One of the reasons might be that affected by the division of parents' roles in the family, mothers bear more parenting responsibilities than fathers and participated more in kids sexual education than fathers (Yang \& Wang, 2018). The study also found that parents' sexual knowledge and attitudes towards sex education were inseparable from their education background. Generally speaking, the higher the parents' education level, the higher the level of knowledge of sexual knowledge and the more positive attitudes towards sex education. Therefore, popularizing scientific sex education through education and propaganda was one of the powerful measures to improve parents' sexual knowledge and attitudes towards sex education.

\section{Recommendations}

Early childhood sex education was not a new issue, and both parents and kindergarten teachers agreed with its importance. While, unfortunately, the topic was rarely been talked in the family or in the kindergarten. Previous studies had pointed out that under the influence of traditional Chinese concepts, teachers did not want to talk or were unwilling to talk, and in the meantime parents did not want to talk and did not know how to talk (Zhang, 2018). An important reason why parents were ashamed to talk about sex was that kindergarten teachers failed to address the topic squarely in parental communication. For example, kindergarten teachers seldom publicized to parents how to guide children to 
learn to protect themselves so as to avoid sexual assault. Therefore, improving parents' knowledge and attitudes towards sex requires parents and teachers to establish a consistent concept of sex education.

Based on the above-mentioned reality and combined with the results of this research, we believe that hierarchical intervention paths can be put forward from three levels: administrative system, school system and family system. Firstly, the administrative system involves the education department and relevant institutions of the women's federation can carry out the training of kindergarten teachers' sex education in the school system, and cultivate seed teachers of early childhood sex education, thus teachers "want to talk, dare to talk and be good at talking" when facing the sexual problems of children and parents. At the same time, education department or women's federation can also integrate resources to compile preschool sex education brochures, reading books, etc., and distribute them to parents to strengthen the popularization of scientific sex education. Secondly, the role of seed teachers in Home-Kindergarten education should be brought into play within the school system. Through special parent-child activities, family education guidance, resource recommendation and other channels, we can publicize children's sexual knowledge to parents, so that parents "want to teach". Especially we pay attention to teaching parents specific family sex education methods, so that parents "dare to teach and be good at teaching". Finally, within the family system, parents should also play their subjective initiative and be responsible for the children's sexual health. On the one hand, parents can actively cooperate with teachers and participate in relevant educational activities organized by kindergarten. On the other hand, parents can improve their knowledge reserve in sex education through reading, internet and others.

\section{Funding}

This research is funded by the 2020 Philosophy and Social Science Research Projects in Colleges of Jiangsu Province "Research on the Training and Development Paths of Early Childhood instructors for 0 - 3 Years" (project number: 2020SJA2418).

\section{Conflicts of Interest}

The author declares no conflicts of interest regarding the publication of this paper.

\section{References}

Berglas, N. F., Jerman, P., Rohrbach, L. A. et al. (2016). An Implementation and Outcome Evaluation of a Multicomponent Sexuality Education Programme for High School Students. Sex Education, 16, 1-19. https://doi.org/10.1080/14681811.2015.1133408

Byers, E. S., Sears, H. A., \& Weaver, A. D. (2008). Parents' Reports of Sexual Communication with Children in Kindergarten to Grade 8. Journal of Marriage and Family, 1, 86-96. https://doi.org/10.1111/j.1741-3737.2007.00463.x

Chuang, C. Y. (2009). The Correlation Study of Parents' Sexual Knowledge, Sexual Edu- 
cation Attitudes and Parental Sexual Education Needs in Kindergartens in Kaohsiung County. Shude University of Science and Technology.

Liu, W. L. (2008). Sex Education for Adolescents in American Families. The Chinese Journal of Human Sexuality January, 1, 15-17.

Liu, W. L., \& Caroline, E. (2007). Survey on Educational Knowledge and Attitudes of Urban Parents to Young Children. Chinese Youth Study, 5, 48-52.

Qin, J. F., \& Li, X. P. (2017). Domestic Infant Sex Education Studies for 20 Years-Based on the Bibliometrics and Visualization Analysis Based on CNKI Datebase. Journal of Zhaotong University, 4, 120-124.

Wilson, E. K., Dalberth, B. T., Koo, H. P. et al. (2010). Parents' Perspectives on Talking to Preteenage Children about Sex. Perspectives on Sexual and Reproductive Health, 42, 56-63. https://doi.org/10.1363/4205610

Yang, L., \& Wang, X. Y. (2018). Foreign Research Progress on the Influencing Factors of Family Sex Education. Chinese Journal of School Health, 11, 162-166.

Zhang, H. M., Yin, X., \& Liu, Y. C. (2019). Investigation and Enlightenment of the Status Quo of Family Sex Education for Primary and Middle School Students. Educational Research and Experiment, 6, 75-79.

Zhang, Y. Y. (2018). Thinking of Sex Education for Children in Kindergarten-From the Perspective of Kindergarten and Family. Journal of Shannxi Xueqian Normal University, 3, 58-63. 